\title{
Two-sided Career Concern and Financial Equilibrium*
}

\author{
Yolanda Portilla ${ }^{\dagger}$ \\ This draft: March 6, 2009
}

\begin{abstract}
This brief paper constructs a model of delegated portfolio management in which two agency relationships are characterized. First, a delegation process from investors to fund companies, and second, a delegation from fund companies to fund managers. Career concerns of both agents lead to a churning equilibrium in which uninformed managers trade noisily, and uninformed fund companies are willing to hire these uninformed managers. This equilibrium delivers non-fully informative prices and a positive and high trading volume. Our model then strengths previous explanations to the trade puzzle, predicting an increasing trade activity as long as institutional investors with intense delegation play an increasing role in financial markets.
\end{abstract}

Key words. career concern; financial equilibrium; trade puzzle.

Journal of Economic Literature. Classification Number: D53, D86, G11, G12, G14, G23

\footnotetext{
* I thank Luis Úbeda for useful comments and suggestions. The usual disclaimer applies.

† Department of Economics, Universidad Carlos III de Madrid, C. Madrid 126, Getafe, 28903, Madrid, Spain. E-mail: yportill@eco.uc3m.es, Tel: +34 (41) 22031 17, Fax: +34 (41) 2522055
} 


\section{Introduction}

One of the most remarkable puzzle in financial economics is the so-called trade puzzle. This puzzle concerns the inability of standard finance paradigm to account for (high) trade observed in financial markets under an environment with asymmetric information. Given the increasing presence of institutional ownership in financial markets during the last fifty years, new explanations to this phenomenon have strongly hinged on the features of this class of investors. ${ }^{1}$

In particular, recent literature on financial economics has recognized the prominent role played by contracts signed by investors and fund companies. Among these works, that of Dasgupta and Prat (2006, [1]) provides an especially interesting framework that explains the puzzle trade based mainly upon two elements. First, they consider the agency problems that emerge when the investor delegates his portfolio management to the fund company. In addition, due to the no observation of the fund manager's ability, they study contracts with implicit incentives given by reputational or career concerns. This setting predicts that the presence of career concerns induces uniformed fund managers to churn, i.e. to trade even when they face a negative expected return. ${ }^{2}$ Noise trade given by churning makes prices to be non-fully informative, which yields a positive trading volume in the asset market.

Dasgupta and Prat treat fund companies and fund managers as the same entity, abstracting then from any agency problem between them. However, as Chevalier and Ellison (1999, [2]) document, the lack of aligned incentives resulting from this delegation process may become very important to the portfolio strategies followed by fund managers. Accordingly, in this paper we extend the set-up of Dasgupta and Prat and study the effects that the additional delegation from fund companies to fund managers can generate on the financial market's equilibrium. Our main result points out that when the reputational costs of both fund companies and fund managers are also considered, the career concern-based explanation for the trade puzzle becomes strong. As a consequence, this paper accounts not only for the increasing trading activity observed in the financial markets during the last decades, but also for the relation of this phenomenon to the increasing participation of institutional investors with more portfolio management delegation inside them (Dow and Gorton 1997, [3]; Cuoko and Kanel 2001, [4]; Chevalier and Ellison 1997, [5], and 1999, [2]).

\footnotetext{
${ }^{1}$ For instance, in the New York Stock Exchange, the percentage of outstanding corporate equity held by institutional investors has increased from 7,2\% in 1950 to 49,8\% in 2002 (NYSE Factbook 2003).

${ }^{2}$ Churning can be defined as to make the account of a client excessively active by frequent purchases and sales primarily in order to generate commissions.
} 
This structure of this paper is as follows. Section 2 presents a model with twosided career concerns contracts between fund companies and fund managers. The next section characterizes the churning equilibrium, and discusses its implications for the trade puzzle. Finally, Section 4 concludes. All the proofs are collected in the Appendix.

\section{The Model}

Consider a two-period economy. The market trades an Arrow security, which has liquidation value $v=0$ or 1 with the same probability of occurrence. This value is revealed at time $t$ and independent across periods. There are a large pool of ex-ante identical fund companies and fund managers ${ }^{3}$. All of them are risk-neutral.

In the first period, one of the fund companies is employed at random by the investor, a single risk-neutral principal. Likewise, this fund company may hire one fund managers and, if so, at the end of the first period she may decide to retain him, hire a challenger of average quality from the pool, or not to hire. Her decision is based on the net return obtained by the fund manager. In the same way, in period 2 , the investor decides to renew the incumbent fund company or hire a new one as she can attempt to infer the ability of the fund company from the outcome of trading.

Therefore, in this environment, we observe two kind of principal-agent contracts: the first one between the investor and the fund company, and the second one between the fund company and the fund manager. In addition, both agency relationships are characterized by reputational or career concerns. This is because present actions taken by both fund companies and fund managers affect their chances of being retained, and thereby, their future compensations.

The fund company can be of two types: talented or untalented. This is represented by $\eta \in\{u, t\}$, with $\operatorname{Pr}(\eta=t)=\zeta$. Similarly, the fund manager can be of two types: good or bad, represented by $\theta \in\{b, g\}$ so that $\operatorname{Pr}(\theta=g)=\gamma$. Ex ante, all types are unknown to fund companies, fund managers and the investor, and are independent of $v$.

Fund managers interact with a large number of risk-neutral short-lived competitive uninformed market makers (hereafter traders). Half of them operate in $t=1$, the other half operate in $t=2$. Fund managers can issue market orders $\left(a_{t}\right)$ to buy one unit of the asset $\left(a_{t}=1\right)$, to sell one unit $\left(a_{t}=0\right)$ or not to trade $\left(a_{t}=\emptyset\right)$. The traders sets ask $\left(p_{t}^{a}\right)$ and bid $\left(p_{t}^{b}\right)$ prices equal to the expected value of $v$ conditional on the observed order history. The bid-ask spread $p_{t}^{a}-p_{t}^{b}$ may be positive, with $p_{t}^{a} \in\left[\frac{1}{2}, 1\right]$

\footnotetext{
${ }^{3}$ Throughout the paper, we refer to the principal as she and the agent as he. Notice that the fund company is the agent in the relationship with the investor and the principal in the labor contract with the manager.
} 
and $p_{t}^{b} \in\left[0, \frac{1}{2}\right]$. Since fund managers are free to choose one of the market markers at random, they are then subject to Bertrand competition. Moreover, for simplicity we assume that traders do not know whether they are in period 1 or $2 .{ }^{4}$

Before contracting, fund companies observe a signal $\tau$ on manager's type. Talented companies observe an informative signal that reveals the true type of the manager. In contrast, untalented companies have access to a noisy signal that does not improve their beliefs on the manager's type. Formally, we have that

$$
\tau(\eta, \theta)= \begin{cases}\theta & \text { if } \eta=t \\ \emptyset & \text { if } \eta=u\end{cases}
$$

Based upon this information, fund companies make a decision $e_{t} \in\{0,1\}$, where $e_{t}=1$ $\left(e_{t}=0\right)$ corresponds to hiring (not to hiring) the manager. Whereas untalented fund companies choose good (bad) fund managers with probability $\gamma$ (with probability $1-\gamma$ ), talented fund companies only choose good fund managers.

The information structure of the fund manager is as follows. At time $t$ a fund manager receives a signal $s$ which can take three values, 0,1 , or $\emptyset$. This signal reveals privately him his true type as it is determined as follows

$$
s(v, \theta)= \begin{cases}v & \text { if } \theta=g \\ \emptyset & \text { if } \theta=b\end{cases}
$$

In order to make a difference between trading and not trading, there exists a cost of trading $\epsilon>0$ paid by the fund manager.

The net return on investment obtained by the fund manager at time $t$ is denoted by $\chi_{t}$, and is defined by

$$
\chi_{t}\left(a, p_{t}^{a}, p_{t}^{b}, v, \epsilon\right)=\left\{\begin{array}{lll}
v-p_{t}^{a}-\epsilon & \text { if } & a=1 \\
p_{t}^{b}-v-\epsilon & \text { if } & a=0 \\
0 & \text { if } & a=\emptyset
\end{array}\right.
$$

Untalented fund companies form a posterior belief about the fund manager's type based upon net returns yield by the portfolio, which is observed at the end of period 1 . Similarly, the investor updates her belief about the fund company's type based on the same information. All of this is formalized by the posterior probabilities $\operatorname{Pr}\left(\theta=g \mid \chi_{t}\right)$ and $\operatorname{Pr}\left(\eta=t \mid \chi_{t}\right)$.

All contractual arrangements between the investor, fund companies and fund managers are exogenously set out. Furthermore, we model payoffs to fund companies and fund managers using a simple linear compensation structure. Accordingly, given the net

\footnotetext{
${ }^{4}$ This means that they are unable to condition thier action of their seniority (see Dasgupta and Prat 2006, [1], p. 11).
} 
return $\chi_{t}$, fees charged by the fund company to the investor correspond to $w_{t}=\delta \chi_{t}+\mu$. Similarly, the payment from the fund company to the manager is given by $\pi_{t}=\alpha \chi_{t}+\beta$. We assume that $\alpha$ and $\delta \in(0,1)$, and $\beta$ and $\mu \in(0, \infty) .^{5}$

Hence, the total investor's payoff is given by ${ }^{6}$

$$
\sum_{t=1}^{2}\left(\chi_{t}-w_{t}\right)
$$

and the total fund company's payoff is

$$
\sum_{t=1}^{2}\left(w_{t}-\pi_{t}\right) .
$$

To summarize, the timing is as follows:

$t=1$

- The investor hires a fund company at random.

- The fund company learns $\tau_{1}$ and chooses a hiring action $e_{1}$.

- The fund manager learns $s_{1}$ and chooses a trading action $a_{1}$.

- Traders observe $a_{1}$ and set prices.

- The investor and the fund company observe the net return yield by the portfolio. All other traders observe $v$. Payments to the fund company and the fund manager are made.

$t=2$

- The investor retains the incumbent fund company or hires a new one.

- The fund company retains the incumbent fund manager or, hires the challenger (chooses a hiring action $\left.e_{2}\right)^{7}$

- The fund manager oberves $s_{2}$ and chooses a trading action $a_{2}$.

- Traders observe $a_{2}$ and set prices.

- The investor and the fund company observe the net return yield by the portfolio. All other traders observe $v$. Payments to the fund company and the fund manager are made.

\section{The Results}

\subsection{The Churning Equilibrium}

In this subsection we characterize a churning equilibrium in which both fund companies and fund managers always trade in the first period. This class of equilibrium is crucial

\footnotetext{
${ }^{5}$ Since both $w_{t}$ and $\pi_{t}$ depend on $\chi_{t}$, the compensation scheme considers the possibility of a penalty whenever $\chi_{t}<0$.

${ }^{6}$ We assume a zero discounting rate.

${ }^{7}$ We will see that in equilibrium this may occur only for untalented fund companies, as talented ones always hire good managers in the first period.
} 
to get both non-fully informative prices and a high trading volume.

Proposition 3.1. For $\alpha, \delta$, and $\epsilon$ low enough, there exists an equilibrium in which:

(i) The investor retains the fund company if the portfolio's return is satisfactory (positive) and replaces him otherwise.

(ii) A talented fund company always both hires good managers and retains them. An untalented fund company hires at random managers, and retains the incumbent manager if and only if the portfolio's return is satisfactory (positive).

(iii) A good fund manager always trades. A bad fund manager churns if $t=1$, and he does not trade if $t=2$.

(iv) Traders set prices

$$
\hat{p}_{t}^{a}=\frac{1}{2}(1+\hat{\gamma}) \text { and } \hat{p}_{t}^{b}=\frac{1}{2}(1-\hat{\gamma})
$$

where

$$
\hat{\gamma}=\frac{2 \zeta+(1-\zeta) \gamma\left(2+\frac{1}{2}(1-\gamma)\right)}{1+\zeta+(1-\zeta) \gamma\left(1+\frac{1}{2}(1-\gamma)\right)}
$$

Proof. See the Appendix

Proposition 3.1 characterizes a churning equilibrium in which all managers trade in the first period. While the good manager trades according to his private information on the asset value, the bad one randomizes between buying and selling.

The investor knows that a successful trade in the first period $\left(\chi_{1}>0\right)$ may stem from a talented fund company (which only hires good managers) or an untalented one. In the second case, this positive return may result from a good manager (with probability $\gamma$ ) or from a churning bad manager with good luck (with probability (1 $\gamma) / 2$ ). All of this suggests her that it is more likely that a successful trade comes from a talented fund company. Consequently, she makes an upward adjustment of her belief on a talented company when she observes $\chi_{1}>0$ so that the posterior becomes higher than the prior, i.e.,

$$
\operatorname{Pr}\left(\eta=t \mid \chi_{1}>0\right) \geq \zeta
$$

Equivalently, the investor knows that an unsuccessful trade in the first period $\left(\chi_{1}<\right.$ $0)$ can only be attributed to an untalented company. In addition, we assume that she believes that no-trade (an event out of the equilibrium path) can also only be associated to a untalented fund company. Based upon this structure of beliefs, the investor retains the first-period fund company if she observes a positive return, and replaces it otherwise.

Since a talented fund company knows perfectly the type of the manager, she only hires good ones. As a consequence, she always observes positive returns and retains the manager. In contrast, an untalented fund company cannot perfectly associate a 
positive return to a good manager. However, she knows that it is more likely that a successful trade comes from a good manager than a bad one. Accordingly, she also makes an upward adjustment on her posterior when positive returns are observed so that

$$
\operatorname{Pr}\left(\theta=g \mid \chi_{1}>0\right) \geq \gamma
$$

Given this structure of beliefs, an untalented fund company retains a manager only if a successful trade is observed at the first period.

A good manager always obtains positive returns whenever transaction costs are low enough $(\epsilon<\widehat{\epsilon})$. Since he knows the true liquidation value of the asset, he always trades correctly and sells or buys according to prices that lie between 0 and 1. Given the structure of beliefs of the game, he knows that his continuation is ensured.

At first period, a bad manager has two alternatives: no-trade or churn. On the one hand, if he does not trade, he makes a zero return and thereby, he is revealed as a bad manager. As a result, he is replaced for sure. On the other hand, although a bad manager yields a negative expected return $(\widehat{\epsilon}-1 / 2-\epsilon)$ when churning, his chance of being retained is $50 \%$. Given a linear compensation structure, a sufficient condition for the bad manager to prefer churning is the fact that the pay-for-performance sensitivity (the parameter $\alpha$ ) be lower than the fixed payment (the parameter $\beta$ ). This occurs because in that case the benefits from being retained (the second-period fixed payment) overcome the costs of churning (a first-period penalty coming from a negative expected return).

Traders cannot distinguish if a market order comes from a good manager or a bad manager who churns at the first-period. The price is then based on the probability that the order is made by a good manager conditional on observing such an order. This probability corresponds to

$$
\begin{aligned}
\hat{\gamma} & =\operatorname{Pr}(\theta=g \mid a \in\{0,1\}) \\
& =\frac{2 \zeta+(1-\zeta) \gamma\left(2+\frac{1}{2}(1-\gamma)\right)}{1+\zeta+(1-\zeta) \gamma\left(1+\frac{1}{2}(1-\gamma)\right)} .
\end{aligned}
$$

It can be verified that the posterior is larger than the prior, i.e., $\hat{\gamma}>\gamma$. The source of this fact is two-fold. First, as discussed above, while good managers are always retained, bad ones may be replaced. Second, even if a bad manager is not replaced, he does not trade in the second period.

Interestingly, the posterior in our model is greater than the posterior resulting from Dasgupta and Prat (2006, [1]) as

$$
\hat{\gamma}>\gamma \frac{5-\gamma}{2+3 \gamma-\gamma^{2}}=\hat{\gamma}_{D \& P},
$$


where $\hat{\gamma}_{D \& P}$ denotes the posterior in Dasgupta and Prat. This is due to the fact that our framework nests the environment studied by these authors as we also incorporate the possibility of talented fund companies that only hire good managers.

As a result, in our model, traders set equilibrium prices that yield a greater bidask spread than that characterized by Dasgupta and Prat. To see that, note that the bid-ask price is given by

$$
\hat{p}_{t}^{a}-\hat{p}_{t}^{b}=\hat{\gamma}
$$

From this, it is clear that the bid-ask spread inherits all the properties of posterior probability, and thus, the result follows. Thus, our bid-ask price is larger than the Dasgupta and Prat's one for all $\gamma \in[0,1)$ and $\zeta>0$. Otherwise, they are equal. This property is illustrated in Figure 1, which shows that, as long as $\zeta>0$ (i.e., there exists talented fund companies), our model delivers a a higher bid-ask spread. ${ }^{8}$ This fact leads us to obtain results that are stronger than those of previous literature in terms of average trading (see Corollary 1 below).

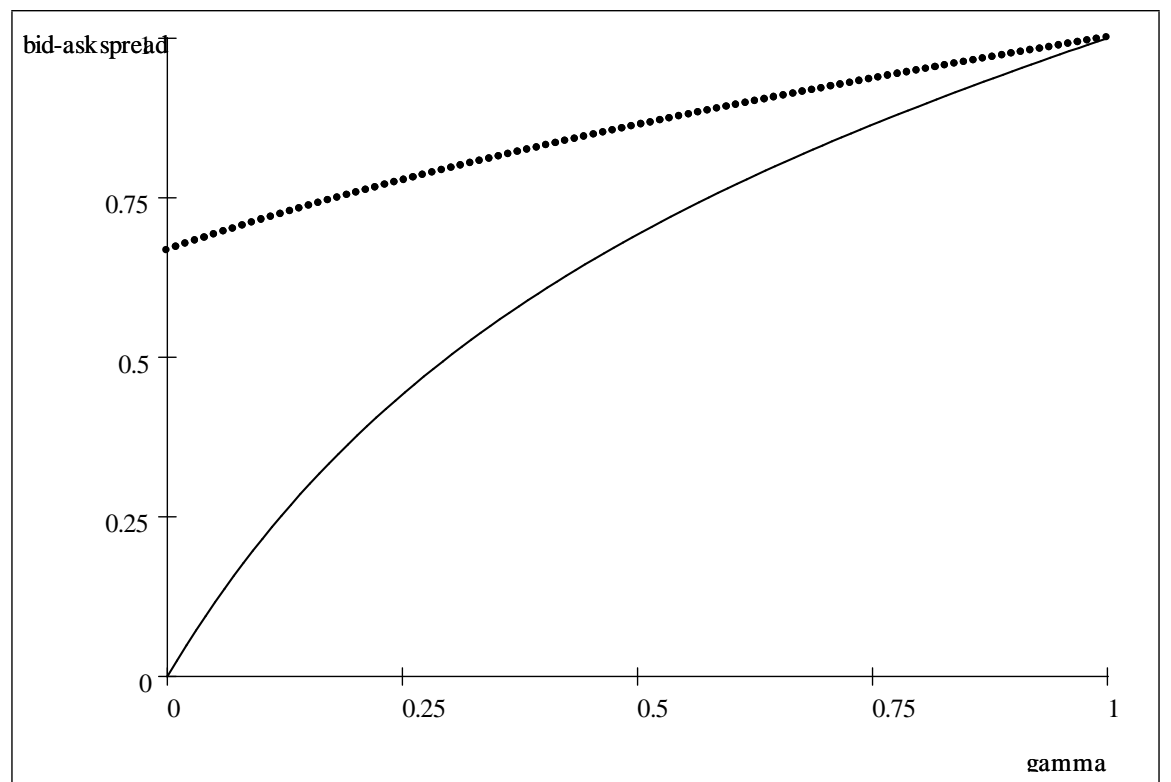

Figure 1. Bid-ask spread of Portilla (2008) with $\zeta=.5$ (dotted line), and Dasgupta and Prat (2006) (solid line).

In addition, note that since the posterior probability of facing a good manager is increasing with the proportion of talented fund companies, the bid-ask spread does so (see Figure 2).

\footnotetext{
${ }^{8}$ Figure 1 is constructed assuming that $\zeta=.5$.
} 


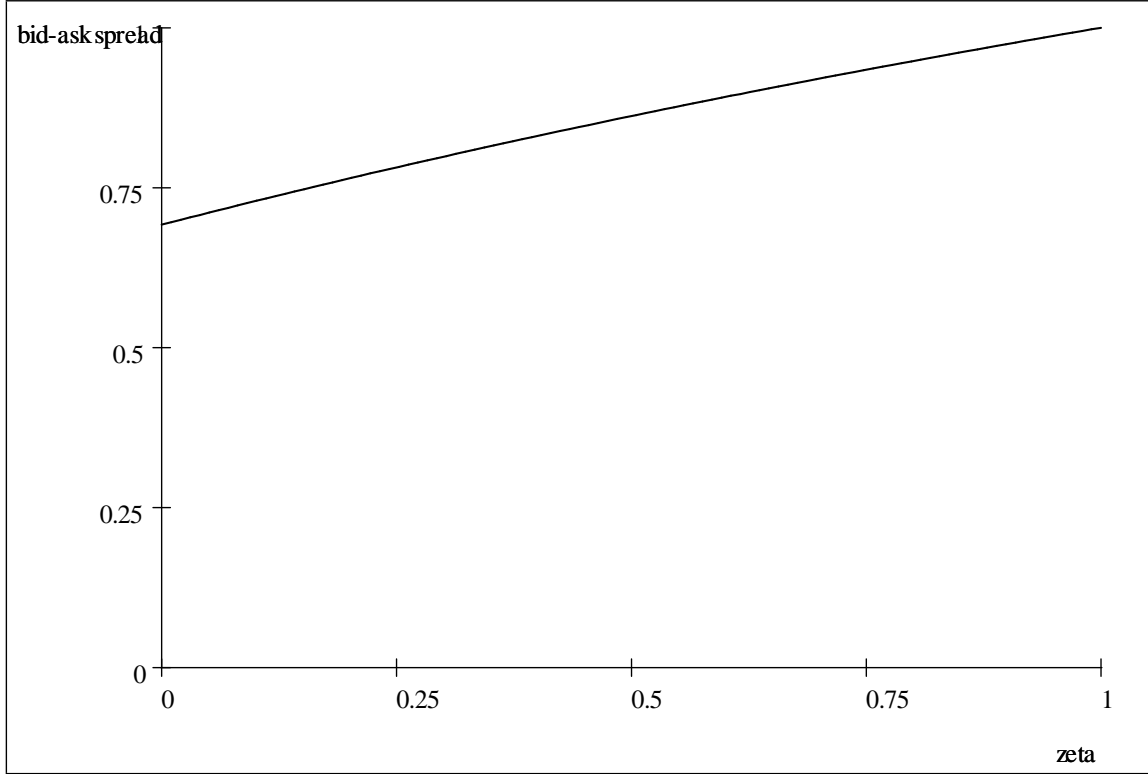

Figure 2. Bid-ask spread and proportion of talented fund companies assuming $\gamma=.5$.

\subsection{Comparative Statics of Trading Volume}

The main implication of Proposition 3.1 is the contribution to explaining the trade puzzle. Trading volume correspond to the expected number of assets traded as average in the two-period horizon. Thus, it is the average of the probability that a trade takes place at $t=1$ and the probability that a trade takes place at $t=2$. From Proposition 3.1 , we compute in the next corollary the trading volume in the churning equilibrium.

Corollary 3.2. The average trading volume in the churning equilibrium is

$$
w=\frac{2+3 \gamma-\gamma^{2}}{4}+\frac{\zeta\left(1-\gamma\left(1+\frac{1-\gamma}{2}\right)\right)}{2} .
$$

Proof. See the Appendix

Some properties of the average trading volume are the following. First, it is positive even when the proportion of good managers tends to zero. This results from the presence of a churning equilibrium, which guarantees that the equilibrium in the financial market is not fully informative. Second, the average trading volume is increasing with the prior of both good managers $(\gamma)$ and talented fund companies $(\zeta)$. This is consistent with the previous results related to the bid-ask spread. Third, our model delivers a trade volume that is higher than the Dasgupta and Prat's one for all $\gamma \in[0,1)$ and $\zeta>0$, and equal otherwise. This is true as it can verified that

$$
w=w_{D \& P}+\frac{\zeta\left(1-\gamma\left(1+\frac{1-\gamma}{2}\right)\right)}{2}
$$


where

$$
w_{D \& P}=\frac{2+3 \gamma-\gamma^{2}}{4}
$$

is the average trading in Dasgupta and Prat (2006, [1]). This fact is also illustrated by Figure 3.

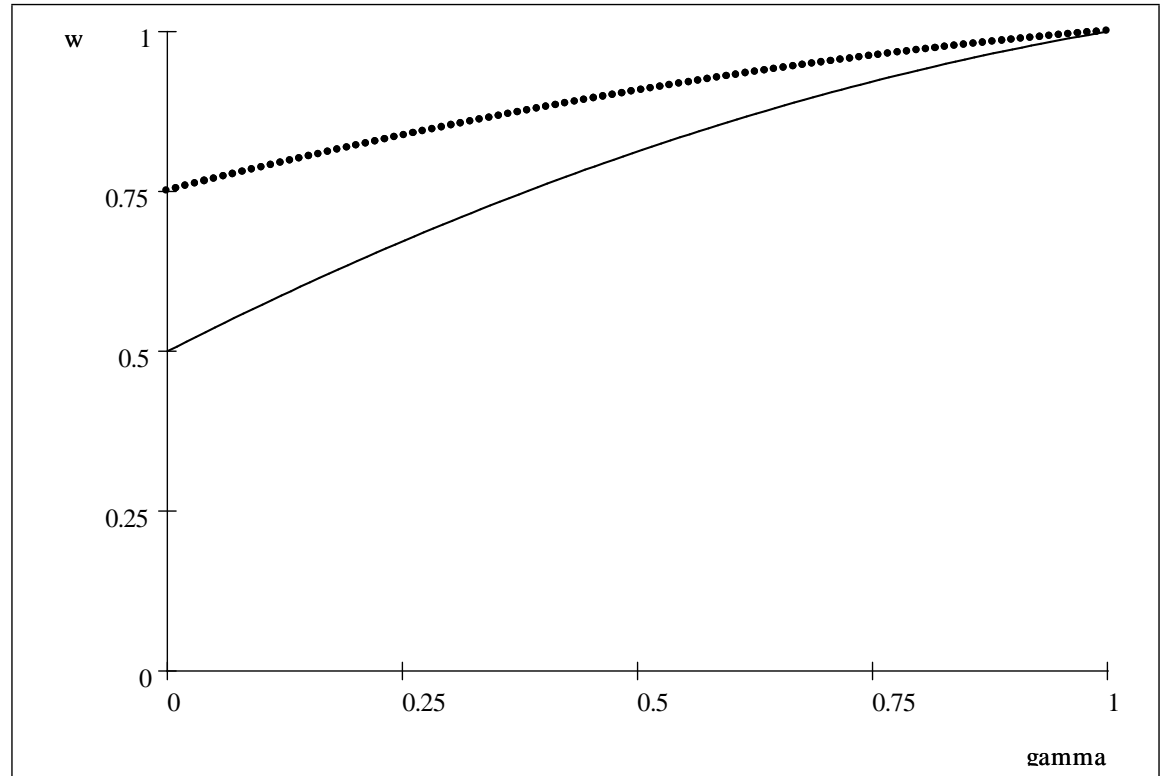

Figure 3. Average trading volume of Portilla (2008) with $\zeta=.5$ (dotted line), and Dasgupta and Prat (2006) (solid line).

Thus, our model allows to account not only for the positive, but also for the large trading activity observed in financial markets working under asymmetric information. The intuition of this result is as follows. The inclusion of an extra delegation stage in the financial contracting process provides us with an additional source of reputational concerns. As a consequence, the two-sided career concerns setup - in particular the presence of talented fund companies- ends up being crucial to strength previous reputational-based explanations of the trading puzzle.

\section{Conclusions}

This paper examines the equilibrium of a financial market in which there are two stages of portfolio management delegation: one from investors to fund companies, and the other one from fund companies to fund managers. In both agency relationships, agents are reputational concerned. That is, they face a positive probability of being fired if their first-period performance (measured in terms of the managed portfolio return) is not satisfactory for the principal. These implicit incentives lead to an uninformed manager to churn if his compensation scheme ensures him a fixed salary sufficiently high. Similarly, these career concern incentives lead to an uninformed fund company to 
hire a manager even knowing that it is likely that he may be uninformed, and thus, he may generate a penalty against her. However, since the presence of churning managers increases the chance of getting a positive return, the chance of being retained by the investor for a fund company does so. As a result, if her compensation structure is so that the fixed component is sufficiently large, an uninformed fund company will decide to (randomly) hire a manager.

This double-sided career concern setup allows a churning equilibrium to emerge in which prices are not fully informative and the trading volume is positive and high. This is then the main contribution of our model: it strengths previous explanations to the trade puzzle based on reputational concerns.

Finally, it is worthy to stress that our model provides results consistent with two stylized facts observed in financial markets during the last decades. First, an increasing participation of institutional investors has been accompanied by increasing trade volumes (Dow and Gorton 1997, [3]). Second, an increase of delegated portfolio management has lead to a higher trading activity (Cuoko and Kanel 2001, [4], Chevalier and Ellison 1997, [5], and 1999, [2]).

\section{Appendix}

Proof of Proposition 3.1. In order to obtain this equilibrium, we use the notion of Subgame Perfect Nash equilibrium (SPNE) and we then apply backward induction. Manager's strategy (at $t=2$ ). At $t=2$, a bad manager never sells since $\hat{p}_{2}^{b}<1 / 2$ guarantees that $\hat{p}_{2}^{b}-1 / 2-\epsilon<0$. Likewise, it can be verified that a bad manager never buys as well because $\hat{p}_{2}^{a}>1 / 2$ ensures that $1 / 2-\hat{p}_{2}^{a}-\epsilon<0$.

A good manager trades as long as transaction costs are low enough. He is strictly better off buying if $1-\hat{p}_{2}^{a}-\epsilon>0$, which is verified if $\epsilon<\frac{1}{2}(1-\hat{\gamma}) \equiv \widehat{\epsilon}$, and strictly better off selling if $\hat{p}_{2}^{b}-\epsilon>0$, which is also satisfied if the same condition for transaction costs holds true.

Untalented fund company's belief. Possible first-period realizations of the net return are the following ones:

(i) Successful purchase or sale: $\chi_{1}=\widehat{\epsilon}-\epsilon>0$ provided that $\epsilon<\widehat{\epsilon}$.

(ii) Wrong purchase or sale: $\chi_{1}=\widehat{\epsilon}-1-\epsilon<0$ because $\widehat{\epsilon}<1$.

(iii) No trade: $\chi_{1}=0$.

Since only (i) and (ii) are observed in equilibrium, we can assume any conjecture for the result out of the equilibrium path. In particular, we assume a null probability. An untalented fund company then requires that their beliefs be consistent with equilibrium 
play which implies that

$$
\operatorname{Pr}\left(\theta=g \mid \chi_{1}\right)=\left\{\begin{array}{cc}
0 \quad \text { if } \chi_{1}<0 \\
\frac{\zeta+\gamma(1-\zeta)}{\gamma \zeta+\frac{1}{2}(1+\gamma)(1-\zeta)} \\
0 \quad \text { if } \chi_{1}=0
\end{array}\right.
$$

which follows from

$$
\begin{aligned}
\operatorname{Pr}(\theta & \left.=g \mid \chi_{1}>0\right)=\frac{\operatorname{Pr}\left(\theta=g, \chi_{1}>0\right)}{\operatorname{Pr}\left(\chi_{1}>0\right)} \\
& =\frac{\zeta+\gamma(1-\zeta)}{\gamma \zeta+\frac{1}{2}(1+\gamma)(1-\zeta)}
\end{aligned}
$$

since

$$
\begin{aligned}
\operatorname{Pr}(\theta & \left.=g, \chi_{1}>0\right)=\operatorname{Pr}\left(\theta=g, \chi_{1}>0 \mid \eta=t\right) \operatorname{Pr}(\eta=t)+ \\
\operatorname{Pr}(\theta & \left.=g, \chi_{1}>0 \mid \eta=u\right) \operatorname{Pr}(\eta=u) \\
& =\zeta+\gamma(1-\zeta)
\end{aligned}
$$

and

$$
\begin{aligned}
\operatorname{Pr}\left(\chi_{1}\right. & >0)=\operatorname{Pr}\left(\chi_{1}>0 \mid \eta=t\right) \operatorname{Pr}(\eta=t)+\operatorname{Pr}\left(\chi_{1}>0 \mid \eta=u\right) \operatorname{Pr}(\eta=u) \\
& =\gamma \zeta+\frac{1}{2}(1+\gamma)(1-\zeta)
\end{aligned}
$$

because

$$
\begin{aligned}
\operatorname{Pr}\left(\chi_{1}\right. & >0 \mid \eta=t)=\operatorname{Pr}\left(\chi_{1}>0 \mid \eta=t, \theta=g\right) \operatorname{Pr}(\theta=g) \\
+\operatorname{Pr}\left(\chi_{1}\right. & >0 \mid \eta=t, \theta=b) \operatorname{Pr}(\theta=b) \\
& =\gamma
\end{aligned}
$$

and

$$
\begin{aligned}
\operatorname{Pr}\left(\chi_{1}\right. & >0 \mid \eta=u)=\operatorname{Pr}\left(\chi_{1}>0 \mid \eta=u, \theta=g\right) \operatorname{Pr}(\theta=g) \\
+\operatorname{Pr}\left(\chi_{1}\right. & >0 \mid \eta=u, \theta=b) \operatorname{Pr}(\theta=b) \\
& =\gamma+\frac{1}{2}(1-\gamma) .
\end{aligned}
$$

Moreover, it is possible to show that $\operatorname{Pr}\left(\theta=b, \chi_{1}>0\right)=0 .{ }^{9}$ The untalented fund company's best response is to retain if and only if the posterior is higher than the prior probability, i.e. if

$$
\operatorname{Pr}\left(\theta=g \mid \chi_{1}\right) \geq \gamma
$$

\footnotetext{
${ }^{9}$ Since a good (bad) manager generates a positive (negative) expected portfolio return.
} 
This is only satisfied by $\operatorname{Pr}\left(\theta=g \mid \chi_{1}>0\right)$ since

$$
\begin{gathered}
\frac{\zeta+\gamma(1-\zeta)}{\gamma \zeta+\frac{1}{2}(1+\gamma)(1-\zeta)} \stackrel{?}{\geq} \gamma \\
\Longleftrightarrow \zeta+\gamma(1-\zeta) \stackrel{?}{\geq} \gamma\left[\gamma \zeta+\frac{1}{2}(1+\gamma)(1-\zeta)\right] \\
\Longleftrightarrow \zeta\left(1-\gamma^{2}\right) \geq \gamma(1-\zeta)\left[\frac{1}{2}(\gamma-1)\right]
\end{gathered}
$$

which is true because the l.h.s. of the last expression is non-negative and the r.h.s. is non-positive.

Thus, the untalented fund company retains the incumbent fund manager if it observes a positive investment performance, and replaces him otherwise.

Talented fund company. Since the talented fund company only hires good managers, it always observes $\chi_{1}>0$ and thus, $\operatorname{Pr}\left(\theta=g \mid \chi_{1}\right)=1$. As a result, this class of fund company always retains the good fund manager.

Investor's belief. The structure of the investor's beliefs is as follows. Possible realizations of the first-period net return imply that

$$
\operatorname{Pr}\left(\eta=t \mid \chi_{1}\right)=\left\{\begin{array}{cc}
0 \quad \text { if } \chi_{1}<0 \\
\frac{\zeta}{\gamma \zeta+\frac{1}{2}(1+\gamma)(1-\zeta)} & \text { if } \chi_{1}>0 \\
0 \quad \text { if } \chi_{1}=0 &
\end{array}\right.
$$

where

$$
\begin{aligned}
\operatorname{Pr}(\eta & \left.=t \mid \chi_{1}>0\right)=\frac{\operatorname{Pr}\left(\eta=t, \chi_{1}>0\right)}{\operatorname{Pr}\left(\chi_{1}>0\right)} \\
& =\frac{\operatorname{Pr}(\eta=t)}{\operatorname{Pr}\left(\chi_{1}>0\right)} \\
& =\frac{\zeta}{\gamma \zeta+\frac{1}{2}(1+\gamma)(1-\zeta)}
\end{aligned}
$$

Moreover, it is possible to show that $\operatorname{Pr}\left(\eta=u, \chi_{1}>0\right)=0^{10}$ The investor's best response is to retain if and only if the posterior is higher than the prior probability, i.e. if

$$
\operatorname{Pr}\left(\eta=t \mid \chi_{1}\right) \geq \zeta
$$

This is only satisfied by $\operatorname{Pr}\left(\eta=t \mid \chi_{1}>0\right)$ since

$$
\begin{aligned}
& \frac{\zeta}{\gamma \zeta+\frac{1}{2}(1+\gamma)(1-\zeta)} \stackrel{?}{\geq} \zeta \\
& \zeta(\gamma-1) \leq(1-\gamma),
\end{aligned}
$$

which is true as the 1.h.s. of this expression is non-positive and the r.h.s. is non-negative. Thus, the investor retains the fund company if it observes a positive result, and replaces

\footnotetext{
${ }^{10}$ Since a good (bad) manager generates a positive (negative) expected portfolio return.
} 
it otherwise.

Fund manager's strategy (at $t=1$ ).

Good manager. If he plays $a_{1}=s$, he generates a successful return at $t=1$, i.e., $\chi_{1}>0$. Thus, the good manager is retained and his portfolio again yields a positive return at $t=2$. The total good fund manager's total payoff corresponds to

$$
\pi_{g}(a=s)=\left(\alpha \chi_{1}+\beta\right)+\left(\alpha \chi_{2}+\beta\right) .
$$

Notice that expected net returns generated by good managers are given by

$$
E\left(\chi_{t} \mid \text { success }\right)=\widehat{\epsilon}-\epsilon
$$

Taking expectation(s) on (5.1) and using (5.2) yields

$$
E \pi_{g}(a=s)=2 \alpha(\widehat{\epsilon}-\epsilon)+2 \beta>0,
$$

which holds as $\epsilon<\widehat{\epsilon}$.

Bad manager. At $t=1$, he has two possibilities: trade (churn) or no trade. If he does not trade in the first period, he is not retained, and then, his payoff is

$$
\pi_{b}(a=\phi)=\beta
$$

On the other hand, if he trades at $t=1$, he successes and fails with the same probability. The expectation of the net return conditional on no successful trade is given by

$$
E\left(\chi_{t} \mid \text { failure }\right)=\widehat{\epsilon}-1-\epsilon<0 .
$$

Thus, the bad fund manager's expected payoff corresponds to

$$
\begin{aligned}
E \pi_{b}(a & =\{0,1\})=\frac{1}{2}\left[E\left(t_{1} \mid \text { success }\right)+t_{2}\right]+\frac{1}{2}\left[E\left(t_{1} \mid \text { failure }\right)\right] \\
& =\frac{1}{2}\left[\alpha E\left(\chi_{1} \mid \text { success }\right)+2 \beta\right]+\frac{1}{2}\left[\alpha E\left(\chi_{1} \mid \text { failure }\right)+\beta\right] \\
& =\frac{1}{2} \alpha\{(\widehat{\epsilon}-\epsilon)+(\widehat{\epsilon}-1-\epsilon)\}+\frac{3}{2} \beta \\
& =-\alpha\left(\frac{\hat{\gamma}}{2}+\epsilon\right)+\frac{3}{2} \beta .
\end{aligned}
$$

Then, the bad manager churns if

$$
E \pi_{b}(a=\{0,1\})>\pi_{b}(a=\phi)=\beta,
$$

which is equivalent to the condition

$$
\alpha \leq \frac{\beta / 2}{\frac{\hat{\gamma}}{2}+\epsilon} .
$$


Since $\epsilon<\widehat{\epsilon}$, a sufficient condition is given by

$$
\alpha \leq \beta .
$$

Trader's Pricing Strategy. The probability that the second-period fund manager is good depends on whether the fund company is talented or untalented in the first period. In the first, case, this probability is one. In the second case, it depends on whether the fund company hires a good or bad manager in the first period. Notice that if an untalented fund company hires a bad manager, it can hire a good manager in the second period if the bad manager gets a unsuccsessful net return at $t=1$. All of this implies that the probability that the second-period fund manager is good corrresponds to

$$
\begin{aligned}
\operatorname{Pr}(\theta & =g, t=2)=\zeta+\left[\gamma+(1-\gamma) \frac{1}{2} \gamma\right](1-\zeta) \\
& =\zeta+(1-\zeta) \gamma\left[1+\frac{1}{2}(1-\gamma)\right]
\end{aligned}
$$

We have three kind of managers: second-period managers who trade only if they are good, first-period good managers who always trade and churners who randomize with the same probability between buying and selling. Thus, by symmetry,

$$
\operatorname{Pr}(\theta=g \mid a=1)=\operatorname{Pr}(\theta=g \mid a=0)=\operatorname{Pr}(\theta=g \mid a \in\{0,1\})
$$

Then, a trader who receives a buy or sell order computes the following posterior probability:

$$
\begin{aligned}
\hat{\gamma} & =\operatorname{Pr}(\theta=g \mid a \in\{0,1\}) \\
& =\frac{\operatorname{Pr}(\theta=g, a \in\{0,1\})}{\operatorname{Pr}(a \in\{0,1\})} \\
& =\frac{\operatorname{Pr}(\theta=g, a \in\{0,1\}, t=1)+\operatorname{Pr}(\theta=g, a \in\{0,1\}, t=2)}{\operatorname{Pr}(a \in\{0,1\}, t=1)+\operatorname{Pr}(a \in\{0,1\}, t=2)}
\end{aligned}
$$

Notice that $\operatorname{Pr}(\theta=g, a \in\{0,1\}, t=1)$ is given by

$$
\begin{aligned}
\operatorname{Pr}(\theta=g, a \in\{0,1\}, t=1 \mid \eta=t) \operatorname{Pr}(\eta & =t)+\operatorname{Pr}(\theta=g, a \in\{0,1\}, t=1 \mid \eta=u) \operatorname{Pr}(\eta=u) \\
& =\zeta+\gamma(1-\zeta)
\end{aligned}
$$

and $\operatorname{Pr}(\theta=g, a \in\{0,1\}, t=2)$ corresponds to

$$
\begin{aligned}
\operatorname{Pr}(\theta=g, a \in\{0,1\}, t=2 \mid \eta=t) \operatorname{Pr}(\eta & =t)+\operatorname{Pr}(\theta=g, a \in\{0,1\}, t=2 \mid \eta=u) \operatorname{Pr}(\eta=u) \\
& =\zeta+\left(\gamma+(1-\gamma) \frac{1}{2} \gamma\right)(1-\zeta) .
\end{aligned}
$$

Moreover,

$$
\operatorname{Pr}(a \in\{0,1\}, t=1)=1,
$$


and

$$
\begin{aligned}
\operatorname{Pr}(a \in\{0,1\}, t=2) & =\operatorname{Pr}(\theta=g, t=2) \\
& =\zeta+\left(\gamma+(1-\gamma) \frac{1}{2} \gamma\right)(1-\zeta)
\end{aligned}
$$

Thus,

$$
\hat{\gamma}=\frac{2 \zeta+(1-\zeta) \gamma\left(2+\frac{1}{2}(1-\gamma)\right)}{1+\zeta+(1-\zeta) \gamma\left(1+\frac{1}{2}(1-\gamma)\right)} .
$$

With this probability, the trader computes the next ask price:

$$
\begin{aligned}
\hat{p}_{t}^{a} & =\operatorname{Pr}(\theta=g \mid a \in\{0,1\}) E(v \mid \theta=g, a=1)+\operatorname{Pr}(\theta=b \mid a \in\{0,1\}) E(v \mid \theta=b, a=1) \\
& =\hat{\gamma}+(1-\hat{\gamma}) \frac{1}{2} \\
& =\frac{1}{2}(1+\hat{\gamma}),
\end{aligned}
$$

and the bid price:

$$
\begin{aligned}
\hat{p}_{t}^{b} & =\operatorname{Pr}(\theta=g \mid a \in\{0,1\}) E(v \mid \theta=g, a=0)+\operatorname{Pr}(\theta=b \mid a \in\{0,1\}) E(v \mid \theta=b, a=0) \\
& =\hat{\gamma} 0+(1-\hat{\gamma}) \frac{1}{2} \\
& =\frac{1}{2}(1-\hat{\gamma}) .
\end{aligned}
$$

Proof of Corollary 3.2. The average trading volume is given by

$$
w=\frac{\operatorname{Pr}(a \in\{0,1\}, t=1)+\operatorname{Pr}(\theta=g, a \in\{0,1\}, t=2)}{2}
$$

where

$$
\operatorname{Pr}(a \in\{0,1\}, t=1)=1,
$$

and

$$
\begin{aligned}
\operatorname{Pr}(\theta=g, a \in\{0,1\}, t=2) & =\operatorname{Pr}(a \in\{0,1\}, t=2) \\
& =\operatorname{Pr}(a \in\{0,1\}, \theta=g, t=2 \mid \eta=t) \operatorname{Pr}(\eta=t) \\
+\operatorname{Pr}(a \in\{0,1\}, \theta=g, t=2 \mid \eta=u) \operatorname{Pr}(\eta & =u) \\
& =\zeta+(1-\zeta)\left(\gamma+(1-\gamma) \frac{\gamma}{2}\right) .
\end{aligned}
$$

Hence,

$$
w=\frac{2+3 \gamma-\gamma^{2}}{4}+\frac{\zeta\left(1-\gamma\left(1+\frac{1-\gamma}{2}\right)\right)}{2} .
$$




\section{References}

[1] Dasgupta, A. and A. Prat (2006). Financial Equilibrium with Career Concerns, Journal of Theoretical Economics 88, pp. 288-307.

[2] Chevalier, J. and G. Ellison (1999). Career Concerns of Mutual Fund Managers, Quarterly Journal of Economics 114(2), pp. 389-432.

[3] Dow, J. and G. Gorton (1997). Noise Trading, Delegated Portfolio Management, and Economic Welfare, Journal of Political Economy 105(5), pp. 1024-1050.

[4] Cuoco, D. and R. Kaniel (2001). Equilibrium Prices in the Presence of Delegated Portfolio Management, Working Paper, University of Pennsylvania, 2001.

[5] Chevalier, J. and G. Ellison (1997). Risk Taking by Mutual Funds as a Response to Incentives, Journal of Political Economy 105(6), pp. 1167-1200. 